\title{
Dilated cardiomyopathy in cats - A case report
}

\author{
Priyanka M. Uppe, K. Jeyaraja and D. Sumathi \\ Department of Clinics \\ Madras Veterinary College, Vepery, Chennai -600007, Tamilnadu \\ Corresponding author: K J eyaraja, email: jaivet72@rediffmail.com \\ Received: 18-08-2012, Accepted: 11-09-2012, Published online: 30-01-2013
}

\begin{abstract}
How to cite this article:
Uppe PM, J eyaraja K and Sumathi D (2013) Dilated cardiomyopathy in cats - A case report, Vet. World 6(4): 226-227, doi: 10.5455/vetworld.2013.226-227
\end{abstract}

\begin{abstract}
Two cats were brought to Madras Veterinary College Teaching Hospital with the history and clinical signs suggestive of congestive heart failure ie, coughing, exercise intolerance, dyspnea, abdominal distension etc. There was history of feeding the cat with home made diet in one case and in other with commercial dog food. Based on electrocardiographic, radiographic and echocardiographic findings, the diagnosis of dilated cardiomyopathy was done in both the cases. The cases were managed with enalapril maleate, furosemide, dietary taurine supplementation and other supportive therapy. Among these two cases, one cat died on $2^{\text {nd }}$ day of treatment and the other showed recovery after 8 days of treatment.
\end{abstract}

Keywords: cardiomyopathy, congestive heart failure, electrocardiography,

\section{I ntroduction}

Cardiomyopathy is any disease involving primarily and predominantly the heart muscle. Acquired myocardial disease or cardiomyopathy is the most important cause of heart failure in cats [1]. Few workers reported that 12 per cent of death in cats was due to cardiomyopathy [2]. Feline myocardial disease appears to be common but its presence may not be detected easily without careful investigation because of long subclinical phase [3]. Based on morphology, cardiomyopathies are classified as dilated cardiomyopathy, hypertrophic cardiomyopathy and restrictive or unclassified cardiomyopathy [4].

Dilated cardiomyopathy is a disease of ventricular muscle characterized by systolic myocardial failure and an enlarged overloaded heart that leads to signs of congestive heart failure or low cardiac output [5]. Taurine deficiency was identified as the primary cause of dilated cardiomyopathy in cats [6]. The cause of taurine deficiency in cats is primarily nutritional it occurs with exclusive feeding of cat with homemade diet or commercially available dog foods [7].

\section{Case history and observations}

Case-1: A four year old nondescript male cat weighing $3.8 \mathrm{~kg}$ was brought to Madras Veterinary College Teaching Hospital with the history of lethargy, inappetence, coughing and respiratory distress since three weeks. Major clinical findings were dyspnea (open mouth breathing), exercise intolerance and muffled cardiac sounds. Pleurocentesis revealed transudate. There was history of feeding the cat with commercial dog food past 1.5 years.

Case-2: Six year old nondescript female cat of body weight $6 \mathrm{~kg}$ was brought to Madras Veterinary College Teaching Hospital with the history of abdominal distension since 10 days. Tachypnea, tachycardia, loud systolic murmur of grade V/VI over left sterna area, fluid thrill in abdominal area were the major clinical findings. Cat was fed with home made diet.

Hematology and serum biochemical parameters were within the normal range in case no.1, where as second cat had mild prerenal azotemia (serum creatinine level- $2.3 \mathrm{mg} / \mathrm{dl}$, BUN- 68). Thoracic radiograph revealed severe pleural effusion masking cardiac silhouette in case no.1. Whereas congestion of pulmonary vessels, left atrial enlargement and cardiomegaly were observed in second cat. Reduced ' $\mathrm{R}$ ' wave amplitude suggesting pleural effusion was observed on electrocardiography in case no.1. Direct ophthalmoscopic examination revealed mild central retinal degeneration in case no.2, whereas case no.1. showed no ophthalmoscopic abnormality.

2-D echocardiography revealed dilatation of all four chambers of heart and reduced left ventricular wall and inter ventricular septal motion in both the cases. Secondary regurgitation of mitral valve was noticed with color flow doppler. Increased LVID d (Case no. $1=2.45 \mathrm{~cm}$, Case no. $2=2.62 \mathrm{~cm}$ ) and LVIDs $($ Case no. $1=2.27 \mathrm{~cm}$, Case no. $2=2.46 \mathrm{~cm})$, decreased shortening fraction (Case no.1 $=8.5 \%$, Case no. $2=7.5 \%$; normal range $20-40 \%$ ). Based on all these findings the diagnosis of dilated cardiomyopathy was made and the cases were differentiated from other cardiomyopathies.

\section{Treatment and discussion}

Therapeutic Pleurocentesis was done and about $100 \mathrm{ml}$ of transudate was removed from Case no. 1 to relieve the respiratory distress. Both the cases were managed with ACE inhibitor enalapril maleate @ $0.5 \mathrm{mg} / \mathrm{kg}$ B.W, PO, bid and furosemide @ $1 \mathrm{mg} / \mathrm{kg}$ B.W, PO, bid. Commercial cat food containing taurine was advised. Dietary salt restriction was also suggested in both cases.

Cases were reviewed regularly. Despite the treatment, 


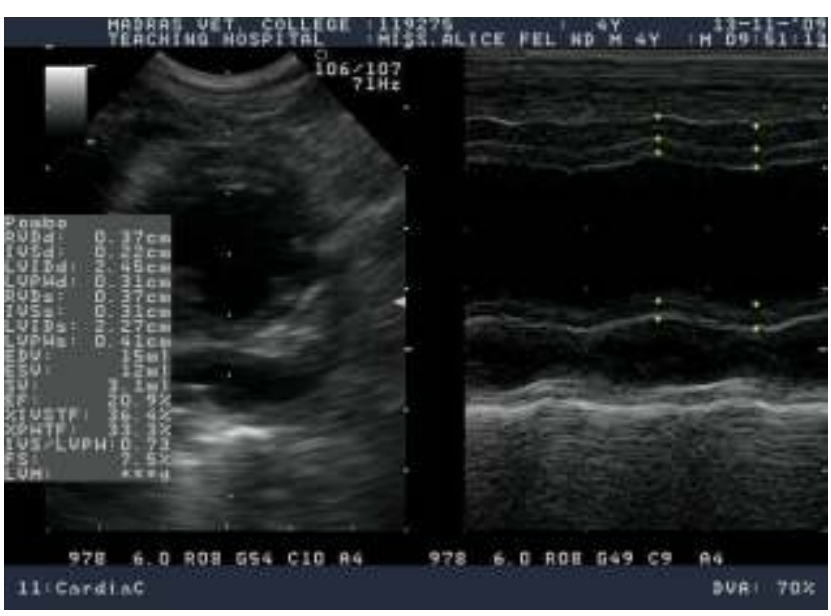

Figure-1. 2-D echocardiograph showing dilated chambers of heart and reduced left ventricular wall and inter ventricular septal motion

Case no. 2 succumbed on $2^{\text {nd }}$ day of post treatment. This might be due to the advance stage of the disease. Moderate clinical improvement was noticed in Case no. 1 after $8^{\text {th }}$ day of treatment. Review radiography and echocardiography was done in case no.1 five weeks post treatment. Radiography revealed the reduction in the pleural effusion 5 weeks after treatment. Shortening fraction was improved from 8.5 per cent to 12.8 per cent. Continuation of medication with regular review was advised.

Myocardium requires taurine for its normal structure and function $[8,9]$. Activity of enzyme (cysteine sulfinic acid decarboxylase) necessary for taurine synthesis is low in cats and in addition taurine is obligatory for conjugation of bile acids in cats [10-12]. All these things make the cat susceptible for taurine deficiency and chronic taurine deficiency results in myocardial failure $[13,14]$. Hence, it is very important to take a note of special nutritional requirements of each species for successful clinical outcome.

\section{References}

1. Trehiou-Sechi, E., Tissier, R., Gouni, V., Misbach, V., Petit, A.M.P., Balouka, D. (2012). Comparative Echocardiographic and Clinical Features of Hypertrophic Cardiomyopathy in 5 Breeds of Cats: A Retrospective Analysis of 344 Cases (2001-2011). J. Vet. Intern. Med., 26: 532-541.

2. Bond, B.R., Fox, P. R. (1984). Advances in feline cardiomyopathy. Vet Clin North Am Small Anim Pract., 14: 10211038.

3. Singletary, G.E., Rush, J.E., Fox, P.R., Stepien, R.L., Oyama, M.A. (2012). Effect of NT-pro- BNPAssay on Accuracy and Confidence of General Practitioners in Diagnosing Heart Failure or Respiratory Disease in Cats with Respiratory

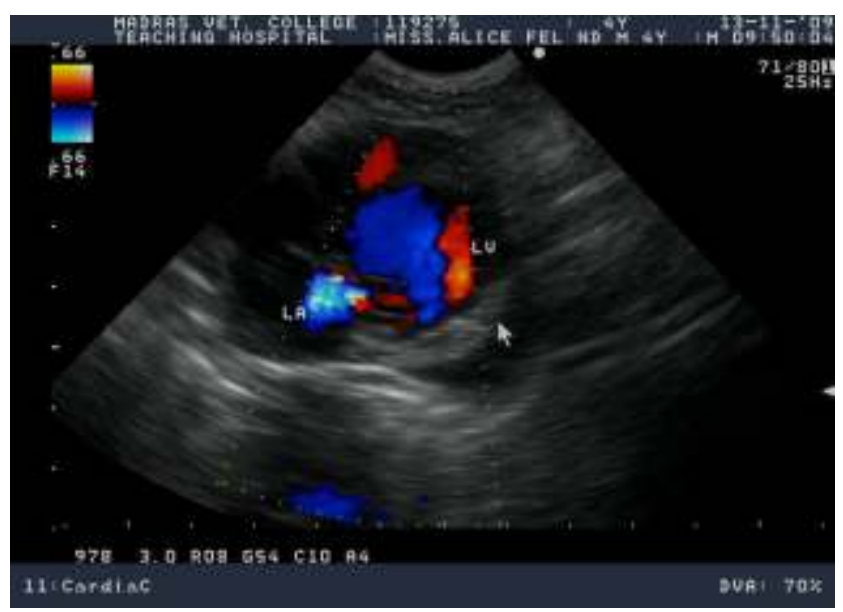

Figure-2. Color doppler showing secondary regurgitation of mitral valve

Signs. J. Vet. Intern. Med., 26: 542-546.

4. Fuentes, V.L. (1993). Cardiomyopathy in cats. In prac., 15: 301-308.

5. Christopher, F. P., Jonathan, A. A., François, E., Lee Pyle, R. (2009). Prevalence of cardiomyopathy in apparently healthy cats. Am. Vet. Med. Assoc., 234:1398-1403.

6. Sisson, D. D., Knight, D. H., Helinski, C., Fox, P, R., Bond, B.R. (2011). Plasma Taurine Concentrations and M-mode Echocardiographic Measures in Healthy Cats and in Cats with Dilated Cardiomyopathy. J. Vet. Intern. Med., 5: 232238.

7. Pion, P.D., Kittleson, M.D., Thomas, W.P., Delellis, L.A. Rogers, Q. R. (1992). Response of cats with dilated cardiomyopathy to taurine supplementation. J. Am. Vet. Med. Assoc., 201: 275-278.

8. Sleeper, M., Lawrence, T. B., Mark, H., Katherine, P. P., Sweeney, L.P. (2011). Status of therapeutic gene transfer to treat cardiovascular disease in dogs and cats. J. Vet. Cardiol., 13: 131-140.

9. Hambrook, L. E., Bennett, P, F. (2012). The effect of pimobendan on the clinical outcome and survival of cats with non-taurine responsive dilated cardiomyopathy. J. Fel. Med. Surg., 3: 28-34.

10. Ferasin, L. (2009). Feline Myocardial Disease. Classification, Pathophysiology and Clinical Presentation. J. Fel. Med. Surg., 11:3-13.

11. Skrodzki, M., Trautvetter, E., Monchi, E. (2009). Plasma Taurine Levels in Healthy Cats and Cats with Cardiac Disorders. J. Nutr., 121:8171-8172.

12. Ferasin, L. (2012). Feline cardiomyopathy. In. Prac., 34: 204-213.

13. Atkins, C.E., Synder. P. S., Keene, B.W. (1990). Efficacy of digoxin for treatment of cats with dilated cardiomyopathy. $J$. Am. Vet. Med.Assoc., 196: 1463-1469.

14. Ferasin, L., Sturgess, C.P., Cannon, M.J., Caney, S.M.A., Gruffydd-Jones, T.J., Wotton, P.R. (2010). Feline idiopathic cardiomyopathy: A retrospective study of 106 cats (20042009). J. Fel. Med. Surg., 5: 151-159. 